\title{
Timing of antenatal care for adolescent and adult pregnant women in south-eastern Tanzania
}

\author{
Karin Gross ${ }^{1,2^{*}}$, Sandra Alba ${ }^{1,2}$, Tracy R Glass ${ }^{1,2}$, Joanna Armstrong Schellenberg ${ }^{3}$ and Brigit Obrist ${ }^{1,2,4}$
}

\begin{abstract}
Background: Early and frequent antenatal care attendance during pregnancy is important to identify and mitigate risk factors in pregnancy and to encourage women to have a skilled attendant at childbirth. However, many pregnant women in sub-Saharan Africa start antenatal care attendance late, particularly adolescent pregnant women. Therefore they do not fully benefit from its preventive and curative services. This study assesses the timing of adult and adolescent pregnant women's first antenatal care visit and identifies factors influencing early and late attendance.
\end{abstract}

Methods: The study was conducted in the Ulanga and Kilombero rural Demographic Surveillance area in southeastern Tanzania in 2008. Qualitative exploratory studies informed the design of a structured questionnaire. A total of 440 women who attended antenatal care participated in exit interviews. Socio-demographic, social, perceptionand service related factors were analysed for associations with timing of antenatal care initiation using regression analysis.

Results: The majority of pregnant women initiated antenatal care attendance with an average of 5 gestational months. Belonging to the Sukuma ethnic group compared to other ethnic groups such as the Pogoro, Mhehe, Mgindo and others, perceived poor quality of care, late recognition of pregnancy and not being supported by the husband or partner were identified as factors associated with a later antenatal care enrolment $(p<0.05)$.

Primiparity and previous experience of a miscarriage or stillbirth were associated with an earlier antenatal care attendance $(p<0.05)$. Adolescent pregnant women started antenatal care no later than adult pregnant women despite being more likely to be single.

Conclusions: Factors including poor quality of care, lack of awareness about the health benefit of antenatal care, late recognition of pregnancy, and social and economic factors may influence timing of antenatal care. Community-based interventions are needed that involve men, and need to be combined with interventions that target improving the quality, content and outreach of antenatal care services to enhance early antenatal care enrolment among pregnant women.

\section{Background}

Maternal death has declined substantially worldwide except in Sub-Saharan Africa [1]. Of the 21 countries with the highest maternal mortality 15 are in subSaharan Africa, including Tanzania [1]. In 2010, pregnancy and childbirth-related complications led to an estimated 454 maternal deaths per 100'000 live births in Tanzania [2]. Most of these complications occur unpredictably during labour, delivery and the immediate postpartum period [3]. Deaths could be averted with prompt

\footnotetext{
* Correspondence: karin.gross@unibas.ch
}

${ }^{1}$ Swiss Tropical and Public Health Institute, Basel, Switzerland

Full list of author information is available at the end of the article and adequate diagnosis and care [4]. However, $49 \%$ of all women in Tanzania still deliver at home without any skilled attendant [2]. Moreover, according to the definition of the World Health Organisation (WHO) [5] a quarter of all women in Tanzania begin childbearing as adolescents before reaching the age of 20 years [2]. An estimated 70'000 adolescent mothers die each year worldwide because their bodies are not yet physically ready for motherhood and due to social disadvantages $[6,7]$. Pregnancy and childbirth thus constitutes the number one killer among 15-19 year old girls worldwide [5].

\section{Biomed Central}


Several studies have shown that women who started antenatal care (ANC) attendance early and attended frequently were more likely to be assisted during delivery by a skilled attendant compared to those who initiated ANC late and attended only few visits [8-11]. Although ANC might not have the potential to predict and avert obstetric emergencies during pregnancy and childbirth, it exposes women to health education on risk factors and encourages them to deliver with a skilled attendant or in a health facility. Recent studies have suggested that women who knew about risk factors were more likely to utilize health facilities for delivery than those without knowledge [10,12]. Moreover, ANC provides the opportunity to detect and treat anomalies of pregnancy and to deliver preventive health services such as immunization against tetanus, prophylactic treatment of malaria and worms, and HIV testing and counselling (leading to Preventing Mother to Child Transmission of HIV, PMTCT) [13]. To fully benefit from these interventions, it is important that women start ANC early on in their pregnancy. The revised Focused Antenatal Care (FANC) model of WHO [13] as well as the Tanzanian FANC guidelines [14] recommend at least four ANC visits for uncomplicated pregnancies with the first visit starting before 16 weeks of gestation [13]. However, an analysis of Demographic and Health Surveys (DHS) from 45 developing countries showed that women in subSaharan Africa start antenatal care considerably later than women from other regions [8]. Similarly, other studies reported late ANC enrolment after more than five months of gestation in sub-Saharan African countries [15-18], including Tanzania [2,10,19,20]. A comparative analysis of the use of maternal health services in subSaharan Africa showed that adolescent mothers initiated ANC attendance even later and had poorer maternal health care than adult mothers [21].

Quantitative studies on timing of ANC attendance from developing countries have been able to shed light on the influence of socio-demographic factors. Although there is mixed evidence, late booking of antenatal care has repeatedly been associated with young age [21-24], premarital status $[21,23]$ unwanted pregnancies $[16,23,25]$, high parity $[16,21,23,26,27]$, lack of formal education [21-23,27], low socio-economic status (SES) $[16,23]$ and ethnicity $[16,27]$. Less is known about the influence of social and cultural determinants on prenatal care use among adult and adolescent pregnant women [28]. Qualitative as well as quantitative studies have stressed the influence of social support from family members [24,29-31]. A study from Nepal for example reported the important role of mothers-in-law in deciding about ANC use of their pregnant daughters-in-law [30]. Studies from Uganda showed that adolescents were more likely to experience violence from parents, to be rejected by their partner, expelled from school, and to be stigmatized [29,32], and therefore to hide their pregnancy [32]. Late recognition of and uncertainty about the pregnancy [33-35], as well as cultural beliefs and practices around pregnancy [34-38], have been reported to influence women's timing of ANC attendance. Ethnographic studies from Mozambique and southern Tanzania illustrated for example that women at an early stage of pregnancy delayed ANC initiation purposely in order to protect the unborn from witchcraft and sorcery attacks of jealous neighbours and kin [36,37]. Other studies showed that women's ANC attendance is mediated by their experiences and the quality of care at earlier ANC visits $[39,40]$. These studies clearly indicate that beyond demographic and socio-economic factors, social and cultural factors as well as individual perception of pregnancy and care impact women's timing of ANC enrolment. Unfortunately, data are often not disaggregated by age, thus hiding particular vulnerabilities and issues [6].

Exploratory studies carried out in the study area in 2007 as a preparation for this study confirmed several of the factors stressed in the literature. In semi-structured interviews [41], health workers reported that women, and in particular women from the ethnic group of the Sukuma - semi-nomadic pastoralists who started to migrate into the region in the 1980s [42] - initiated ANC attendance late and underutilized ANC due to lack of education and living in distant settlements. Data collected between 2007 and 2009 from the Health Management Information System (HMIS) of the health facilities within the study area [41] indicated that the proportion of pregnant women who initiated ANC attendance after the fifth month of gestation rose from $53 \%$ to $56 \%$ between 2006 and 2008. Over this period, 18\% of all ANC attendees were 19 years old or less. In an in-depth study with a small sample of recent adult and adolescent mothers (Gross 2007, unpublished data), adolescent women were found to visit the ANC clinic later and less frequently than adult women. Moreover, adolescent mothers differed from adult mothers in several ways: most of them were in their first pregnancy which was unplanned and prior to marriage, they still lived at their parents' home and they did not get any social or economic support from their partner or the child's father.

Based on the insights from the literature review and the exploratory studies, three main research questions arose that are addressed in this paper: First, do pregnant women - and in particular adolescent pregnant women start ANC attendance late? Second, what factors are associated with early or late ANC attendance? And finally, do adolescent pregnant women differ from adult pregnant women in terms of social and economic support? 


\section{Methods \\ Study setting}

Data collection took place in the Kilombero and Ulanga rural Demographic Surveillance System (DSS) site in south-eastern Tanzania between June and October 2008. The area consists of 25 villages and has been extensively described elsewhere [41,43-46]. At the time of study, the area encompassed an estimated population of nearly 94,000 [47] and was served by a total of 13 first and second-level health facilities. Out of these, 12 (ten public health facilities and two faith-based) facilities provided ANC services on a weekly or daily basis from Monday to Friday. Two district hospitals outside the study area serve as referral centres for complicated cases. The local health system runs a cost-sharing scheme from which pregnant women and children under five years of age are exempted. Besides the biomedical system, traditional birth attendants and traditional healers provide alternative sources of prenatal and delivery care in the area [47].

\section{Sample size and sampling procedures}

A total of 440 pregnant women visiting an ANC clinic were recruited for a cross-sectional study using exit interviews. Ten facilities (nine government facilities and one faith based facility, five in the Kilombero district and five in the Ulanga district) were selected and visited for one day once per month. Since accessibility to health services in this rural context is constrained by seasonal conditions such as weather, agricultural work or availability of money, the exit interviews were conducted over several months. Two other health facilities in the study area (one government facility and one faith based facility) were not included in the study due to low levels of ANC attendance. On average, 12 randomly selected pregnant women were interviewed per visit (min-max: 1-21) adding up to a total of 43 pregnant women interviewed per health facility (min-max: 28-79). No formal sample size calculation was performed.

\section{Data collection}

Two trained local female field workers interviewed the women. A questionnaire was used including closed and some open ended questions Additional file 1. The design of the questionnaire was informed by insights from the exploratory studies as well as findings from the literature. Questions focused on a) socio-demographic characteristics, b) women's knowledge about ANC services, perceived quality of care and motivation to attend the ANC clinics, c) social and cultural factors, and d) ANC service utilization. Information on perceived quality of care and health worker attitudes was only obtained from pregnant women who had attended an
ANC clinic before the day of interview. Additionally, data on the number and timing of ANC visits received were copied from the ANC cards of all women. The questionnaire was designed in English, translated into Swahili, back-translated and pre-tested outside the study area.

\section{Data analysis}

Data from the exit interviews were double-entered using Microsoft Access, validated with EpiInfo version 3.3.2 (EpiInfo Association, Denmark) and analysed in Stata 10 (StataCorp, College Station, Texas, USA).

To answer the first research question - whether pregnant women attended late - the mean gestational age of the foetus at the first visit was calculated and compared to national guidelines. For the comparison of means, ttests were used. For the second research question what factors were associated with an earlier or later ANC attendance - univariate and multivariate linear regression was used. All pre-specified variables with at least a 5\% response in a category were included in the models. Two multivariate regression models were run. The first one included all variables. Since the sample size was substantially decreased by the high number of missing values for the variables on perceived quality of care and perceived health worker $(\mathrm{N}=289)$, a second regression model excluding the two variables served as a sensitivity analysis $(\mathrm{N}=372)$. The gestational age of the foetus in months at the first ANC visit served as the outcome measure. Data on the gestational age of the foetus was collected in gestational weeks from the ANC cards but had to be transformed into gestational months (assuming one month to encompass four weeks) to get a normal distribution needed for the regression analysis. The regression assessed associations between the women's timing of ANC initiation and socio-demographic, social, perception- and service related variables. Associations between variables were assessed with logistic regression models. To answer the third research question - whether adolescent pregnant women differed from adult pregnant women in terms of social and economic support - logistic regression models were fitted to understand associations between adolescent-hood and social and economic support received during pregnancy.

\section{Ethical considerations}

The study was conducted within the frame of the ACCESS Programme which was cleared by the National Institution for Medical Research of Tanzania (NIMR/ HQ/R.8c/Vol. I/66) [48]. Approval was further provided by the review boards of the Swiss Tropical and Public Health Institute (SwissTPH) and the Ifakara Health Institute (IHI). The study was authorized by the district 
coordinators of Reproductive-and-Child-Health ( $\mathrm{RCH})$ and the health facility staff granted permission to conduct the study at their facilities. All study participants provided oral informed consent after having been explained the purpose of the study and informed of their right to withdraw from the study at any time.

\section{Results}

\section{Study population}

Out of the 440 pregnant women who participated in the cross-sectional study, 35 women were excluded - 10 women because their ANC cards did not contain information on gestational age and 25 because information on their age was missing. The final sample consisted of a total of 405 participants, including 61 (15\%) adolescents aged 19 years or younger. Table 1 summarizes the characteristics by age groups. The median age of all respondents was 25 years (Inter-quartile range $(\mathrm{IQR})=$ 21-31) and 18 years (IQR $=17-19)$ among adolescents. Of all women interviewed, $20 \%$ were in their first pregnancy (primiparity); the median number of pregnancies was 3 (IQR $=2-5$, including the current pregnancy). Among adolescent women, $79 \%$ were pregnant for the first time, and the median number of pregnancies was 1 $(\mathrm{IQR}=1-1)$. A quarter of women $(25 \%)$ reported a history of miscarriage or stillbirth. Most women (88\%) were married or lived in a consensual union and 55\% had completed 7 years of primary school. Women belonged to a wide mix of ethnic groups with the Pogoro (19\%), Sukuma (17\%), Mhehe (10\%) and Mgindo (9\%) being the most common.

\section{Timing and reasons of ANC enrolment}

Among the 405 pregnant women participating, only 29\% initiated ANC attendance within the first four months of pregnancy as recommended by WHO [13] and the Tanzanian FANC guidelines [14]. Table 2 shows that overall pregnant women made their first ANC visit at a mean of $5.1(\mathrm{SD}=1.2$, range $=2-9)$. Adolescent pregnant women started slightly earlier with a mean of 5.0 months $(\mathrm{SD}=1.2$, range $=2-8)$. It is noteworthy that the 13 multiparous adolescents in the sample initiated ANC attendance considerably later with an average of $5.5(\mathrm{SD}=1.20, \mathrm{t}=1.43 ; \mathrm{p}=0.157)$ gestational months (data not shown).

When asked about their self-perceived timing of the first ANC visit, $56 \%$ of the participants said that they had made their first ANC visit late. Women who judged their first visit to be late attended ANC significantly later than women who perceived their first visit to be early (mean 5.5 gestational months vs. 4.7 months, $\mathrm{t}=$ 6.92, $\mathrm{p}<0.001$ ). Reasons given for late attendance were: not recognizing the pregnancy early $(29 \%)$; poor accessibility due to distance, difficulties to cross rivers or poor road conditions (17\%); not being able to come due to illness or other obligations such as travelling, caring for a sick person or agricultural work (14\%); or negligence or apathy (13\%). Women who said that they enrolled early in ANC did so in order to follow nurses' advise and because one is supposed to do so (37\%); to know health status and prevent health problems (31\%); out of fear that the consequences of non-compliance would lead to not being treated or being scolded by the health facility staff (16\%); or to treat a health problem (15\%).

\section{Determinants of timing of ANC enrolment}

Socio-demographic factors Table 3 shows the results of the univariate and multivariate linear regression for all women. Being in the first pregnancy was strongly associated with an earlier ANC attendance. On average, primiparous women first visited ANC 0.87 month or three weeks earlier than multiparous women $(\mathrm{p}<0.001)$. On the other hand we found no evidence of an association between timing of ANC attendance and adolescent age $(\mathrm{p}=0.462)$. After adjusting for other factors, women who had a previous miscarriage or stillbirth attended 2 weeks earlier compared to women who had not experienced such an incident $(\mathrm{p}=0.007)$. Although univariate analysis for all ethnic groups revealed some slight differences in the timing of first ANC attendance (results not shown), it was only statistically significant for members of the ethnic group of the Sukuma. Multivariate analysis revealed that compared to all other ethnic groups, being a member of the ethnic group of the Sukuma had a strong delaying effect on ANC initiation of three weeks $(\mathrm{p}<0.001)$. There was no evidence that education $(\mathrm{p}=$ $0.987)$ or marital status $(\mathrm{p}=0.532)$ were associated with an earlier or later timing of ANC attendance.

Knowledge and perception of antenatal care Neither women who said that ANC attendance should be initiated within the first three months of pregnancy (67\%) nor those who had a good knowledge about ANC services (22\%) were found to start ANC attendance earlier than the others. Although only few women criticized the quality of ANC services (9\%), multivariate analysis showed that those who did so initiated ANC attendance an average of three weeks later compared to those who were satisfied by the quality $(\mathrm{p}=0.009)$. Criticism was related to lack of services; being sent back home without receiving services due to the lack of sufficient staff; and having to purchase drugs, cards or diagnostic tests despite the national exemption policy that guarantees free health services for pregnant women. Surprisingly, perceived poor attitudes of health workers were associated with two weeks earlier attendance, although the effect was only marginally significant $(p=0.082)$. Few women sought treatment from sources other than ANC (9\%) which was not associated with a late ANC initiation. Univariate logistic regression models revealed that 
Table 1 Characteristics of the sample

\begin{tabular}{|c|c|c|c|c|c|c|c|c|c|}
\hline \multirow[b]{2}{*}{ Categories } & \multicolumn{3}{|c|}{ Total sample } & \multicolumn{3}{|c|}{ Sample of adult women } & \multicolumn{3}{|c|}{ Sample of adolescent women } \\
\hline & $\mathbf{N}$ & $\mathbf{n}$ & $\%$ & $\mathbf{N}$ & $\mathbf{n}$ & $\%$ & $\mathbf{N}$ & n & $\%$ \\
\hline \multicolumn{10}{|l|}{ Socio-demographic characteristics } \\
\hline Age & 405 & & & 344 & & & 61 & & \\
\hline$<20$ years & & 61 & 15 & & & & & 61 & 100 \\
\hline 20-34 years & & 288 & 71 & & 288 & 84 & & & \\
\hline $35-49$ years & & 56 & 14 & & 56 & 16 & & & \\
\hline Parity & 405 & & & 344 & & & 61 & & \\
\hline 1 & & 82 & 20 & & 34 & 10 & & 48 & 79 \\
\hline $2-4$ & & 218 & 54 & & 205 & 60 & & 13 & 21 \\
\hline $5+$ & & 105 & 26 & & 105 & 30 & & & \\
\hline Marital status & 404 & & & 343 & & & 61 & & \\
\hline Married/Consensual union & & 357 & 88 & & 315 & 92 & & 42 & 69 \\
\hline Single or separated & & 47 & 12 & & 28 & 8 & & 19 & 31 \\
\hline History of abort/stillbirth & 402 & & & 342 & & & 60 & & \\
\hline Abort/stillbirth & & 99 & 25 & & 95 & 28 & & 4 & 7 \\
\hline No abort/stillbirth & & 303 & 75 & & 247 & 72 & & 56 & 93 \\
\hline Education level & 402 & & & 341 & & & 61 & & \\
\hline No or incomplete education & & 180 & 45 & & 156 & 46 & & 24 & 39 \\
\hline Primary + & & 222 & 55 & & 185 & 54 & & 37 & 61 \\
\hline Ethnicity & 405 & & & 344 & & & 61 & & \\
\hline Sukuma & & 68 & 17 & & 55 & 16 & & 13 & 21 \\
\hline Other ethnic group & & 337 & 83 & & 289 & 84 & & 48 & 79 \\
\hline
\end{tabular}

ANC knowledge and perception

Perceived ANC starting time

Within first 3 months

After first 3 months

Knowledge of services

$$
\begin{aligned}
& \text { Low } \\
& \text { High }
\end{aligned}
$$

Perceived service quality

$$
\begin{aligned}
& \text { Good } \\
& \text { Bad }
\end{aligned}
$$

Perceived health worker attitudes

$$
\text { Good }
$$$$
\mathrm{Bad}
$$

Traditional medicine use Yes

$$
\text { No }
$$

Pregnancy perception

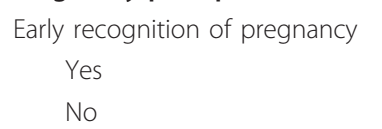

Waiting for quickening Yes

$$
\text { No }
$$

Social and economic support

Money

Yes

No

Advice received to attend ANC

Yes

$\begin{array}{ll}256 & 63 \\ 148 & 37\end{array}$

404

196
327

222

105

344

$260 \quad 76$

$84 \quad 24$

266

241

25

258

310

402

$\begin{array}{ll}291 & 94 \\ 19 & 6\end{array}$

341

$\begin{array}{ll}239 & 93 \\ 19 & 7\end{array}$

$37 \quad 9$

$365 \quad 91$

404

343

$284 \quad 70$

$120 \quad 30$

403

$108 \quad 27$

$295 \quad 73$

68

32

$\begin{array}{ll}31 & 9 \\ 310 & 91\end{array}$

$\begin{array}{ll}240 & 70 \\ 103 & 30\end{array}$

342

$\begin{array}{ll}94 & 27 \\ 248 & 73\end{array}$

56

61

$34 \quad 61$

6

53

52

61

\section{6}

55

10

90

61

61

$44 \quad 72$

$17 \quad 28$

$14 \quad 23$

$\begin{array}{ll}47 & 77\end{array}$


Table 1 Characteristics of the sample (Continued)

\begin{tabular}{|c|c|c|c|c|c|c|c|c|c|}
\hline No & & 229 & 57 & & 214 & 62 & & 15 & 25 \\
\hline Accompanied to clinic & 405 & & & 344 & & & 61 & & \\
\hline Yes & & 196 & 48 & & 162 & 47 & & 34 & 56 \\
\hline No & & 209 & 52 & & 182 & 52 & & 27 & 44 \\
\hline Supported by husband & 405 & & & 344 & & & 61 & & \\
\hline Yes & & 380 & 94 & & 324 & 94 & & 56 & 92 \\
\hline No & & 25 & 6 & & 20 & 6 & & 5 & 8 \\
\hline
\end{tabular}

women who reported that they had visited a traditional healer were more likely to have had a history of a reproductive loss $(\mathrm{OR}=2.90, \mathrm{p}=0.003)$ or to belong to the Sukuma ethnic group $(\mathrm{OR}=1.96, \mathrm{p}=0.09)$.

Knowledge and perception of pregnancy Almost a third of the women interviewed (30\%) said that they had not recognized early that they were pregnant, some of them because of continued bleeding or previous use of contraception. Multivariate regression showed that women's late perception of pregnancy was independently associated with a later ANC start of 2 weeks ( $\mathrm{p}=$ $0.002)$. About a quarter of all women (27\%) reported that they had waited for the foetus to move (quickening) before initiating ANC attendance. Although waiting for the quickening was not associated with a later ANC attendance $(p=0.323)$ in the first regression model, it became marginally associated $(\mathrm{p}=0.088)$ with a later ANC start of one week in the sensitivity analysis that also included women attending the clinic for the first time in their life (data not shown).

Social and economic support Table 3 illustrates the negative influence of lacking social and economic support on the timing of ANC initiation: In particular not possessing money in cash when attending the ANC clinic ( $p=0.064$ ) and not receiving support from the husband/partner ( $\mathrm{p}=0.035$ ) were independently associated with a later ANC enrolment in the multivariate analysis for all women. Women who had no money in hand attended on average about 1 week later and women who felt not supported by their husband attended almost 3 weeks later than women who did receive such support. In the sensitivity analysis including women who attended the ANC clinic for the first time in their life - not possessing money in cash when attending the ANC clinic became significantly associated with a later start of one week $(p=0.037)$ whereas there was not effect anymore for not receiving support from the husband/partner $(\mathrm{p}=0.149$, data not shown).

\section{Social and economic support for adolescent women}

Table 4 shows that adolescent pregnant women were less likely to be married or to live with their partner than adult pregnant women $(\mathrm{p}<0.001)$. They were more likely to receive advice to attend the ANC ( $\mathrm{p}<$ 0.001 ) and to have received this advice from their mother, or a close person they called 'mother', rather than from their partner compared to adult women (data not shown, OR $=9.83, \mathrm{p}<0.001)$.

\section{Discussion}

This study showed that $71 \%$ of the pregnant women initiated ANC attendance after the recommended four months of pregnancy, at an average of 5.1 months (Table 2). This is consistent with the national average of 5 gestational months reported among facility users [19]. A DSS household survey conducted in the study area around the same time found a similar average of 5.02 gestational months at women's first ANC visit [47].

Adolescent pregnant women have been reported to most likely either not attend ANC or to attend late and infrequently $[5,6,21,23,31,49]$ due to lack of knowledge, lack of power to take decisions, lack of money, or cultural factors including local concepts of illness [5]. Contrary to the findings of these studies and our exploratory studies, we found no evidence of delayed attendance in adolescents (Table 2 and 3). In line with an early study from the US that reported lower prenatal care utilization among adolescents in their second pregnancy [50] multiparous adolescents were found to start ANC attendance considerably later. Due to the study design of using exit interviews, we could only obtain information on women's timing of their first ANC visit and were unable to assess their overall utilization of ANC or even non-attendance. A study from Uganda

Table 2 Pregnant women's timing of ANC initiation

\begin{tabular}{lllllllll}
\hline & \multicolumn{3}{l}{ Total sample } & & \multicolumn{2}{c}{ Sample of adult women } & \multicolumn{3}{c}{ Sample of adolescent women } \\
\hline Categories & N & Mean & SD & N & Mean & SD & N & Mean \\
\hline $\begin{array}{l}\text { Mean gestational month at } \\
\text { first ANC visit }\end{array}$ & 404 & 5.1 & 1.2 & 344 & 5.1 & 1.2 & 61 & 5.0 \\
\hline
\end{tabular}


Table 3 Estimated effect of socio-demographic, social and perception- and service related factors on timing of pregnant women's first ANC visit in months

\begin{tabular}{|c|c|c|c|c|c|c|}
\hline & \multicolumn{3}{|c|}{ Univariate } & \multicolumn{3}{|c|}{ Multivariate $(\mathrm{N}=289)$} \\
\hline & Coeff $^{b}$ & $(95 \% \mathrm{Cl})$ & p-value & Coeff $^{b}$ & $(95 \% \mathrm{Cl})$ & p-value \\
\hline \multicolumn{7}{|l|}{ Maternal factors } \\
\hline \multicolumn{7}{|l|}{ Parity $(N=405)$} \\
\hline Primi & -0.47 & $(-0.76,-0.18)$ & 0.002 & -0.87 & $(-1.32-0.42)$ & $<0.001$ \\
\hline \multicolumn{7}{|l|}{ Multi ${ }^{a}$} \\
\hline \multicolumn{7}{|l|}{ Adolescent/adult $(N=405)$} \\
\hline Adolescent & -0.14 & $(-0.48,0.19)$ & 0.406 & 0.18 & $(-0.30,0.65)$ & 0.462 \\
\hline \multicolumn{7}{|l|}{ Adult ${ }^{\mathrm{a}}$} \\
\hline \multicolumn{7}{|l|}{ Marital status $(\mathrm{N}=404)$} \\
\hline \multicolumn{7}{|l|}{ Married/Consensual union ${ }^{a}$} \\
\hline Single & 0.01 & $(-0.36,0.39)$ & 0.947 & 0.15 & $(-0.33,0.63)$ & 0.532 \\
\hline \multicolumn{7}{|l|}{ History of abort/stillbirth ( $N=402)$} \\
\hline \multicolumn{7}{|l|}{ No abort ${ }^{a}$} \\
\hline One or more abort & -0.23 & $(-0.51,0.05)$ & 0.107 & -0.46 & $(-0.79,-0.13)$ & 0.007 \\
\hline \multicolumn{7}{|l|}{ Education level $(N=405)$} \\
\hline No or incomplete formal education & 0.03 & $(-0.21,0.27)$ & 0.811 & 0.00 & $(-0.29,0.29)$ & 0.987 \\
\hline \multicolumn{7}{|l|}{ Primary $+{ }^{a}$} \\
\hline \multicolumn{7}{|l|}{ Ethnicity ( $N=405)$} \\
\hline Sukuma & 0.54 & $(0.23,0.86)$ & 0.001 & 0.82 & $(0.44,1.19)$ & $<0.001$ \\
\hline \multicolumn{7}{|l|}{ Other ethnic group ${ }^{a}$} \\
\hline \multicolumn{7}{|c|}{ ANC expectations, knowledge and perceived quality } \\
\hline \multicolumn{7}{|c|}{ Perceived ANC timing $(\mathrm{N}=383)$} \\
\hline \multicolumn{7}{|l|}{ Within first 3 months ${ }^{a}$} \\
\hline After first 3 months & 0.09 & $(-0.17,0.36)$ & 0.498 & -0.05 & $(-0.35,0.24)$ & 0.727 \\
\hline \multicolumn{7}{|l|}{ Knowledge of services $(\mathrm{N}=405)$} \\
\hline \multicolumn{7}{|l|}{ Low $^{a}$} \\
\hline High & 0.30 & $(0.01,0.59)$ & 0.042 & 0.09 & $(-0.23,0.41)$ & 0.572 \\
\hline \multicolumn{7}{|l|}{ Perceived service quality ( $N=319$ ) } \\
\hline \multicolumn{7}{|l|}{ Good $^{\mathrm{a}}$} \\
\hline Bad & 0.79 & $(0.30,1.27)$ & 0.002 & 0.78 & $(0.20,1.36)$ & 0.009 \\
\hline \multicolumn{7}{|l|}{ Perceived health worker attitudes $(N=310)$} \\
\hline \multicolumn{7}{|l|}{ Good $^{\mathrm{a}}$} \\
\hline Bad & 0.08 & $(-0.50,0.67)$ & 0.778 & -0.57 & $(-1.21,0.07)$ & 0.082 \\
\hline \multicolumn{7}{|l|}{ Traditional medicine use $(\mathrm{N}=402)$} \\
\hline Yes & -0.31 & $(-0.73,0.11)$ & 0.142 & -0.07 & $(-0.55,0.41)$ & 0.759 \\
\hline $\mathrm{No}^{\mathrm{a}}$ & & & & & & \\
\hline
\end{tabular}

Pregnancy perception

Early recognition of pregnancy $(N=404)$

Yes $^{a}$

No

0.42

$(0.16,0.68)$

0.002

0.47

$(0.17,0.77)$

0.002

Waiting for quickening ( $N=403$ )

Yes

$0.21 \quad(-0.06,0.48)$

0.130

0.15

$(-0.15,0.45)$

0.323

$\mathrm{No}^{\mathrm{a}}$

Social and economic support

Money ( $\mathrm{N}=404)$

Yes $^{a}$

No

0.27

$(0.02,0.52)$

0.036

0.28

$(-0.02,0.58)$

0.064

Advised to attend ANC $(N=404)$

Yes

$-0.11$

$(-0.35,0.14)$

0.386

$-0.11$

$(-0.40,0.18)$

0.449 
Table 3 Estimated effect of socio-demographic, social and perception- and service related factors on timing of pregnant women?'?s first ANC visit in months (Continued)

Accompanied to clinic $(\mathrm{N}=405)$
$\quad$ Yes
$\quad$ No
Supported by husband $(\mathrm{N}=405)$
$\quad$ Yes
$\quad$ No

${ }^{a}$ Reference category, ${ }^{b}$ Estimated effect derived from linear regression on the timing of the first ANC visit expressed as gestational age in months (f.e. primiparous women started ANC on average 0.47 month earlier than multiparous women). The coefficients in the multivariate model are adjusted for all listed variables

comparing ANC attendance in adolescent and adult first time mothers found no difference in the timing of the first visit but a lower number of subsequent ANC visits in adolescents [29]. Similarly, Magadi et al. [21] found more variation by age with regard to frequency of ANC attendance than with timing. Little is known about adolescents ANC attendance in Tanzania, suggesting studies are needed to investigate their overall attendance.

Second, insights into factors influencing pregnant women's timing of ANC have been provided. Besides primiparity, having a history of a previous reproductive loss was found to be a strong predictor for an earlier ANC initiation in this study (Table 3 ). In accordance with other studies reporting that maternal care use varies across ethnic groups $[16,47]$, the findings showed that the Sukuma ethnic group tended to have their first ANC visits later. Since Sukuma people live in very remote settlements of the study area, the effect is likely to be confounded by distance. GPS data is collected for each household within the DSS area, but unfortunately, it was not possible to merge this information with the demographic information collected during this study. Therefore neither data on distance between the homestead and the health facilities nor on women's socio-economic status were available for analysis. Some studies have reported an association between maternal secondary education and early timing of ANC initiation $[21,51]$. Contrary to these studies there was no evidence of such an effect in this study most presumably due to the overall low education level in the area, where few attend secondary school (see Table 1).

Women were well aware about their timing of ANC attendance, suggesting that confusion about the recommended starting time was not a problem. Few women (22\%) could name more than four ANC services, but contrary to expectations, neither knowledge about correct ANC timing nor good knowledge of ANC services were associated with early ANC attendance (Table 3 ). Knowledge about available services might thus not imply that women are aware of the services' benefits.

Table 4 Estimated effect of being an adolescent on social/economic support

\begin{tabular}{|c|c|c|c|c|c|}
\hline & Adolescent women & Adult women $^{a}$ & & & \\
\hline & $\mathrm{n}$ & $\mathrm{n}$ & $\mathrm{OR}^{\mathrm{b}}$ & $(95 \% \mathrm{Cl})$ & p-value \\
\hline \multicolumn{6}{|l|}{ Social and economic support } \\
\hline \multicolumn{6}{|l|}{ Marital status } \\
\hline Married/Consensual Union ${ }^{a}$ & 42 & 315 & & & \\
\hline Single & 19 & 28 & 5.09 & $(2.62-9.90)$ & $<0.001$ \\
\hline \multicolumn{6}{|l|}{ Money } \\
\hline Yes $^{a}$ & 35 & 200 & & & \\
\hline No & 26 & 122 & 1.35 & $(0.77-2.34)$ & 0.293 \\
\hline \multicolumn{6}{|l|}{ Advice received to attend ANC } \\
\hline Yes & 46 & 129 & 5.09 & $(2.73-9.48)$ & $<0.001$ \\
\hline $\mathrm{No}^{\mathrm{a}}$ & 15 & 214 & & & \\
\hline \multicolumn{6}{|l|}{ Accompanied to clinic } \\
\hline Yes & 34 & 162 & 1.42 & $(0.82-2.45)$ & 0.214 \\
\hline $\mathrm{No}^{\mathrm{a}}$ & 27 & 182 & & & \\
\hline \multicolumn{6}{|l|}{ Supported by husband } \\
\hline Yes $^{\mathrm{a}}$ & 56 & 324 & & & \\
\hline No & 5 & 20 & 1.45 & $(0.52-4.01)$ & 0.478 \\
\hline
\end{tabular}

${ }^{\mathrm{a}}$ reference category, ${ }^{\mathrm{b}}$ Estimated effect of being an adolescent on social and economic support derived from logistic regression 
This matches with the surprisingly large number of women (53\%) who indicated that they had attended ANC early because everyone does so, because of nurses' advice or because they feared the consequences of noncompliance with nurses' rules. In the exploratory study women indicated that their principal reason for attending the ANC clinic was to obtain an ANC card which was perceived as a necessary 'entry ticket' for services during delivery and illness rather than any conviction that ANC was good for their own or their child's health. The important pull factor of the ANC card has previously been reported by studies from Tanzania [20,52], South Africa [35], Malawi [34] and Uganda [40,53]. Attending ANC to obtain an ANC card thus might be one precautionary measure for women to conform to nurses' rules and to avoid harassment or informal payment requirements $[53,54]$. The extremely high rate of overall ANC attendance with 99.6\% [47] and an average of 3.1 visits to ANC clinics over the course of their pregnancy (personal communication: M. Alexander) reported from the area, suggests that by creating informal rules nurses successfully force women to attend the ANC clinics, however not necessarily at an early point of time. This is of course no reason to excuse nor to foster negative attitudes on the side of the nurses towards their clients, but rather calls for better health education in health facilities, outreach services and in the community. Trained focal persons such as TBAs, religious leaders and other opinion leaders working as community volunteers in close collaboration with existing community structures and health services have been found to be effective promoters of obstetric care but also of early and frequent utilization of ANC in Southern Tanzania [55].

Perceived quality of care was generally high among the participants compared to a study from Kenya where almost a third of women complained about incomplete and inadequate services [31]. Considering that ANC services were of similarly low quality in the study area [56], women's high appraisal of the quality of ANC services rather reflects their low expectations of health care services. The fact that the interviewees were recruited at the health facility and interviewed in the proximity of the health facilities also potentially affected women's answers. Among those who were not satisfied with the services provided, perceived poor quality was, however, a strong predictor for late ANC attendance (Table 3). The findings indicate that quality of care, including patient-provider-relationship, plays a critical role in determining a woman's utilization of health care services, and needs to be improved but also better understood. In particular patient-provider-relationships should be further investigated through observational in-depth studies.
Late recognition of pregnancy was found to be a strong predictor of delayed ANC attendance in this study (Table 3). Similarly, late recognition of pregnancy and subsequent delay of ANC attendance has also been reported among South African women who received long acting hormonal contraceptives in the form of injections [33]. Although pregnancy tests seem to be available at drug shops in the study area at a price of between 500-1000 TSh ( 0.30-0.60 USD) they are not widely used (personal communication: I. Mayumana). More than a quarter of participating women said they waited for the quickening before initiating ANC attendance. However, due to the limitation of quantitative methods to investigate topics that need more in-depth inquiry and trust for people to discuss them openly, this study was not able to explain whether women only waited to ensure pregnancy or also due to other reasons. Studies from Tanzania and other sub-Saharan countries have shown that late disclosure of the pregnancy due to local practices or beliefs such as witchcraft is common and has a negative influence on the timing of ANC attendance $[34,36,37,55]$.

The study provides evidence for the negative influence of lacking social and financial support on women's timing of their first ANC visit and the key role of the husband or partner. The results legitimize the attempts of the Tanzanian Ministry of Health and Social Welfare to encourage greater male involvement in maternal health issues [57-59] in the sense that they are better informed about maternal health risks and live up to the expectations of support towards their children and their mothers. It is important, however, that this effort does not stop at policy level but reaches down to the health facility and community level. The community-based intervention conducted in Southern Tanzania found that in particular the equal inclusion of male community volunteers to promote obstetric care and early and frequent ANC use during home visits was an effective strategy to involve and inform men [55]. Supporting income generating activities for women such as revolving funds might be a suitable mean to reduce delay due to lack of economic means needed for ANC or other maternal health services particularly among women who lack support from their husband or partner.

Third, exploratory analysis comparing adolescent and adult pregnant women in terms of social and economic support during pregnancy confirmed that adolescent pregnant women were less likely to be married than adult pregnant women. These findings are in line with a study from Uganda reporting that adolescent first time mothers were more disadvantaged in terms of their likelihood to be rejected by partners [29]. On the other hand, in line with a study from Kenya [31], adolescents in this study were more likely to receive advice to attend 
the ANC clinic than adult women. However, this advice was mostly given by their mother than by their husband, partner or the child's father. These findings suggest that close family members rather than the husbands, partners and child fathers play an important role in supporting adolescent pregnant women. The fact that lacking support from the husband or partner showed no significant effect in the sensitivity analysis that included young women who visited the ANC clinic for the first time (data not shown) further supports this argument.

While the support of relatives seems to be sufficient for adolescents to initiate ANC around the same time as adult pregnant women, the consequences of disadvantages in terms of social and economic support on the overall ANC attendance and - even more importantly for delivering with skilled attendance and postnatal care for themselves and their child needs to be further investigated.

\section{Conclusions}

The majority of pregnant women delayed ANC attendance starting at an average of five months gestation. Adolescents had no greater delay in ANC initiation than adult pregnant women despite being more likely to be single. However, first ANC attendance at four months is recommended, so it is likely that some women missed important services offered during ANC such as preventive health measures, risk screening and health education.

This study found that many women rather attended due to norms and rituals than awareness about the health benefit of prenatal care; and that they delayed ANC initiation due to late perception of pregnancy, perceived bad quality of care and lack of social and economic support. These findings call for combined interventions at the community and health system level. Promotion of early and frequent ANC utilization through communitybased interventions - involving also male community volunteers - could potentially be scaled up at low cost and adapted to local needs. Supporting income generating activities for women such as revolving funds might complement the approach in order to reduce delay due to lack of economic means needed for ANC or other maternal health services. At the same time, the quality of antenatal care services needs to be improved to attract women to use medical care throughout pregnancy, birth and the postpartum period; outreach services should be offered on a regular basis in order to bring services closer to women living in very distant settlements; and informal rules created by health workers in order to force women to attend the ANC clinic should be replaced with informing women about the benefits of maternal health services, but also the use of pregnancy tests.

\section{Additional material}

Additional file 1: Questionnaire.

\section{Acknowledgements}

We thank all the women for their willingness to participate in this study and the district authorities for their cooperation and interest. The study was funded by the Swiss Commission for Research Partnerships in Developing Countries (KFPE), the Novartis Foundation for Sustainable Development and the Rudolf-Geigy Foundation of the Swiss Tropical and Public Health Institute. None of the funders had a role in study design, data collection and analysis, decision to publish, or preparation of the manuscript. We acknowledge the institutional support of the Ifakara Health Institute. Special thanks go to all members of the ACCESS Programme, especially Judith John, Irene Ngoja and Hilda Mwakabusi, and to Phemy Muhaku, Prudenciana Kassim, Lucy Ngwatali and Salum Mbunda for their help with data entry, transcription and translation. We also thank the two reviewers for their helpful and constructive comments and inputs.

\section{Author details}

${ }^{1}$ Swiss Tropical and Public Health Institute, Basel, Switzerland. ${ }^{2}$ University of Basel, Basel, Switzerland. ${ }^{3}$ London School of Hygiene and Tropical Medicine, London, UK. 'University of Basel, Institute of Anthropology, Basel, Switzerland.

\section{Authors' contributions}

KG was responsible for the design and implementation of the study, carried out the data collection, the data management and analysis, and wrote the manuscript. SA assisted with data management, statistical analysis and contributed to the interpretation of the results and the discussion of the manuscript. TRG supported statistical analysis and commented on the manuscript. JS and BO supported the design and coordination of the study and contributed to the discussion of the manuscript. All authors have read and approved the final manuscript.

\section{Competing interests}

The authors declare that they have no competing interests.

Received: 30 September 2011 Accepted: 21 March 2012 Published: 21 March 2012

\section{References}

1. Hogan MC, Foreman KJ, Naghavi M, Ahn SY, Wang M, Makela SM, Lopez AD, Lozano R, Murray CJ: Maternal mortality for 181 countries, 1980-2008: a systematic analysis of progress towards Millennium Development Goal 5. Lancet 2010, 375:1609-1623.

2. National Bureau of Statistics, ICF Macro: Tanzania Demographic and Health Survey 2010 Dar es Salaam: NBS and ICF Macro; 2011.

3. Ronsmans C, Graham WJ: Maternal mortality: who, when, where, and why. Lancet 2006, 368:1189-1200.

4. Campbell OM, Graham WJ: Strategies for reducing maternal mortality: getting on with what works. Lancet 2006, 368:1284-1299.

5. WHO: Pregnant adolescents: delivering on global promises of hope Geneva: WHO; 2006.

6. Bearinger $L H$, Sieving RE, Ferguson J, Sharma V: Global perspectives on the sexual and reproductive health of adolescents: patterns, prevention, and potential. Lancet 2007, 369:1220-1231.

7. Mayor S: Pregnancy and childbirth are leading causes of death in teenage girls in developing countries. BMJ 2004, 328:1152.

8. Abou-Zahr CL, Wardlaw TM: Antenatal care in developing countries: promises, achievements and missed opportunities. An analysis of trends, levels and differentials, 1990-2001 Geneva: World Health Organization; 2003.

9. Bloom SS, Lippeveld T, Wypij D: Does antenatal care make a difference to safe delivery? A study in urban Uttar Pradesh, India. Health Policy Plan 1999, 14:38-48.

10. Mpembeni RN, Killewo JZ, Leshabari MT, Massawe SN, Jahn A, Mushi D, Mwakipa $H$ : Use pattern of maternal health services and determinants of 
skilled care during delivery in Southern Tanzania: implications for achievement of MDG-5 targets. BMC Pregnancy Childbirth 2007, 7:29.

11. Rockers PC, Wilson ML, Mbaruku G, Kruk ME: Source of antenatal care influences facility delivery in rural Tanzania: a population-based study. Matern Child Health J 2009, 13:879-885.

12. Stekelenburg J, Kyanamina S, Mukelabai M, Wolffers I, van Roosmalen J: Waiting too long: low use of maternal health services in Kalabo, Zambia. Trop Med Int Health 2004, 9:390-398.

13. Villar J, Bergsjo P: WHO Antenatal Care Randomized Trial: Manual for the Implementation of the New Model Geneva: WHO; 2002.

14. Ministry of Health Tanzania (RCHS/NMCP) \& JHPIEGO: Focused Antenatal Care. Malaria and Syphilis during Pregnancy. Orientation Package for Service Providers Dar es Salaam: Ministry of Health; 2004.

15. Kiwuwa MS, Mufubenga P: Use of antenatal care, maternity services, intermittent presumptive treatment and insecticide treated bed nets by pregnant women in Luwero district, Uganda. Malar J 2008, 7:44.

16. Magadi MA, Madise NJ, Rodrigues RN: Frequency and timing of antenatal care in Kenya: explaining the variations between women of different communities. Soc Sci Med 2000, 51:551-561.

17. Ndidi EP, Oseremen IG: Reasons given by pregnant women for late initiation of antenatal care in the niger delta, Nigeria. Ghana Med J 2010, 44:47-51.

18. Okunlola MA, Ayinde OA, Owonikoko KM, Omigbodun AO: Factors influencing gestational age at antenatal booking at the University College Hospital, Ibadan, Nigeria. J Obstet Gynaecol 2006, 26:195-197.

19. Marchant T, Bruce J, Nathan R, Mponda H, Sedekia Y, Hanson K: Monitoring and evaluation of the Tanzanian National Voucher Scheme: Report on 2007 TNVS Household, Facility services and Facility users surveys (a comparison across three survey years) Dar es Salaam and London: Ifakara Health Research and Development Centre and London School of Hygiene and Tropical Medicine; 2008.

20. Mrisho M, Obrist B, Schellenberg JA, Haws RA, Mushi AK, Mshinda H, Tanner M, Schellenberg D: The use of antenatal and postnatal care: perspectives and experiences of women and health care providers in rural southern Tanzania. BMC Pregnancy Childbirth 2009, 9:10

21. Magadi MA, Agwanda AO, Obare FO: A comparative analysis of the use of maternal health services between teenagers and older mothers in subSaharan Africa: evidence from Demographic and Health Surveys (DHS). Soc Sci Med 2007, 64:1311-1325.

22. Adekanle DA, Isawumi Al: Late antenatal care booking and its predictors among pregnant women in South Western Nigeria. Online J Health Allied Scs 2008, 7:4.

23. McCaw-Binns A, La Grenade J, Ashley D: Under-users of antenatal care: a comparison of non-attenders and late attenders for antenatal care, with early attenders. Soc Sci Med 1995, 40:1003-1012.

24. McCray TM: An issue of culture: the effects of daily activities on prenatal care utilization patterns in rural South Africa. Soc Sci Med 2004 59:1843-1855

25. Marston C, Cleland J: Do unintended pregnancies carried to term lead to adverse outcomes for mother and child? An assessment in five developing countries. Popul Stud (Camb) 2003, 57:77-93.

26. Adewunmi A, Rabiu K, Tayo A: Gestational age at antenatal booking in Lagos, South-West Nigeria. Internet J Gynecology and Obstetrics 2009, 12:1.

27. Matthews Z, Mahendra S, Kilaru A, Ganapathy S: Antenatal care, careseeking and morbidity in rural Karnataka, India: results of a prospective study. Asia-Pacific Popul Stud 2001, 16:11-28.

28. Ryan JA, Casapia M, Aguilar E, Silva H, Joseph SA, Gyorkos TW: Comparison of prenatal care coverage in early adolescents, late adolescents, and adult pregnant women in the Peruvian Amazon. Int I Gynaecol Obstet 2009, 107:162-165

29. Atuyambe L, Mirembe F, Tumwesigye NM, Annika J, Kirumira EK, Faxelid E: Adolescent and adult first time mothers' health seeking practices during pregnancy and early motherhood in Wakiso district, central Uganda. Reprod Health 2008, 5:13.

30. Simkhada B, Porter MA, Van Teijlingen ER: The role of mothers-in-law in antenatal care decision-making in Nepal: a qualitative study. BMC Pregnancy Childbirth 2010, 10:34.

31. van Eijk AM, Bles HM, Odhiambo F, Ayisi JG, Blokland IE, Rosen DH, Adazu K, Slutsker L, Lindblade KA: Use of antenatal services and delivery care among women in rural western Kenya: a community based survey. Reprod Health 2006, 3:2.
32. Mbonye AK, Neema S, Magnussen P: Preventing malaria in pregnancy: a study of perceptions and policy implications in Mukono district, Uganda. Health Policy Plan 2006, 21:17-26.

33. Jewkes R, Abrahams N, Mvo Z: Study of health care seeking practices of pregnant women in Cape Town. Report four: Summary of findings, conclusions and policy action Tygerberg: CERSA - Women's Health; 1998.

34. Launiala A, Honkasalo ML: Ethnographic study of factors influencing compliance to intermittent preventive treatment of malaria during pregnancy among Yao women in rural Malawi. Trans R Soc Trop Med Hyg 2007, 101:980-989.

35. Myer $\mathrm{L}$, Harrison A: Why do women seek antenatal care late? Perspectives from rural South Africa. J Midwifery Womens Health 2003, 48:268-272.

36. Chapman RR: Endangering safe motherhood in Mozambique: prenatal care as pregnancy risk. Soc Sci Med 2003, 57:355-374.

37. Haws RA, Mashasi I, Mrisho M, Schellenberg JA, Darmstadt GL, Winch PJ: "These are not good things for other people to know": how rural Tanzanian women's experiences of pregnancy loss and early neonatal death may impact survey data quality. Soc Sci Med 2010, 71:1764-1772.

38. Mathole T, Lindmark G, Majoko F, Ahlberg BM: A qualitative study of women's perspectives of antenatal care in a rural area of Zimbabwe. Midwifery 2004, 20:122-132.

39. Audo MO, Ferguson A, Njoroge PK: Quality of health care and its effects in the utilisation of maternal and child health services in Kenya. East Afr Med J 2005, 82:547-553.

40. Ndyomugyenyi R, Neema S, Magnussen P: The use of formal and informal services for antenatal care and malaria treatment in rural Uganda. Health Policy Plan 1998, 13:94-102.

41. Gross K, Alba S, Schellenberg J, Kessy F, Mayumana I, Obrist B: The combined effect of determinants on coverage of intermittent preventive treatment of malaria during pregnancy in the Kilombero Valley. Tanzania Malar J 2011, 10:140.

42. Haddelsey L, Johnson N, Kapapa L, Makoti J, Starkey M: Section 5: Social survey. In Kilombero Valley Wildlife Project. Edited by: Starkey M. Aberdeen: University of St Andrews; 1997:

43. Armstrong Schellenberg J, Mukasa O, Abdulla S, Marchant T, Lengeler C, Kikumbih N, Mshinda H, Nathan R: Chapter 11. Ifakara DSS, Tanzania. In Population and Health in Developing Countries. Population, Health, and Survival at INDEPTH Sites. Volume Volume 1. Edited by: INDEPTH Network. Ottawa: International Development Research Centre; 2002:.

44. Hausmann Muela S: Community understanding of malaria, and treatmentseeking behaviour, in a holoendemic area of southeastern Tanzania Basel: University of Basel, Philosophisch-Naturwissenschaftliche Fakultät; 2000.

45. Hetzel MW, Iteba N, Makemba A, Mshana C, Lengeler C, Obrist B, Schulze A, Nathan R, Dillip A, Alba S, Mayumana I, Khatib RA, Njau JD, Mshinda H: Understanding and improving access to prompt and effective malaria treatment and care in rural Tanzania: the ACCESS Programme. Malar J 2007, 6:83

46. Schellenberg JR, Abdulla S, Minja H, Nathan R, Mukasa O, Marchant T, Mponda H, Kikumbih N, Lyimo E, Manchester T, Tanner M, Lengeler C KINET: a social marketing programme of treated nets and net treatment for malaria control in Tanzania, with evaluation of child health and longterm survival. Trans R Soc Trop Med Hyg 1999, 93:225-231.

47. Spangler SA, Bloom SS: Use of biomedical obstetric care in rural Tanzania: the role of social and material inequalities. Soc Sci Med 2010, 71:760-768.

48. ACCESS Programme: Annual Report 2007/2008 Ifakara: Ifakara Health Institute; 2008.

49. Treffers PE, Olukoya AA, Ferguson BJ, Liljestrand J: Care for adolescent pregnancy and childbirth. Int J Gynaecol Obstet 2001, 75:111-121.

50. Blankson ML, Cliver SP, Goldenberg RL, Hickey CA, Jin J, Dubard MB: Health behavior and outcomes in sequential pregnancies of black and white adolescents. JAMA 1993, 269:1401-1403.

51. Ochako R, Fotso JC, Ikamari L, Khasakhala A: Utilization of maternal health services among young women in Kenya: insights from the Kenya Demographic and Health Survey, 2003. BMC Pregnancy Childbirth 2011, 11:1.

52. Roth Allen D: Managing motherhood, managing risk. Fertility and danger in West Central Tanzania Ann Arbor (Mich.): University of Michigan Press; 2004.

53. Amooti-Kaguna B, Nuwaha F: Factors influencing choice of delivery sites in Rakai district of Uganda. Soc Sci Med 2000, 50:203-213. 
54. Mushi AK: Rural Southern Tanzania: Socio-cultural perspectives for delivery and uptake of preventive child health interventions London: University of London, London School of Hygiene \& Tropical Medicine; 2009.

55. Mushi D, Mpembeni R, Jahn A: Effectiveness of community based Safe Motherhood promoters in improving the utilization of obstetric care. The case of Mtwara Rural District in Tanzania. BMC Pregnancy Childbirth 2010, 10:14.

56. Gross K, Schellenberg JA, Kessy F, Pfeiffer C, Obrist B: Antenatal care in practice: an exploratory study in antenatal care clinics in the Kilombero Valley, south-eastern Tanzania. BMC Pregnancy Childbirth 2011, 11:36.

57. Ministry of Health: National Package of Essential Reproductive and Child Health Interventions in Tanzania Dar es Salaam: Ministry of Health; 2000.

58. Ministry of Health: National policy guidelines for reproductive and child health services Dar es Salaam: Ministry of Health; 2003.

59. Ministry of Health and Social Welfare: The National Road Map Strategic Plan to Accelerate Reduction of Maternal, Newborn and Child Deaths in Tanzania 2008-2015 Dar es Salaam: Ministry of Health and Social Welfare; 2008.

\section{Pre-publication history}

The pre-publication history for this paper can be accessed here: http://www.biomedcentral.com/1471-2393/12/16/prepub

doi:10.1186/1471-2393-12-16

Cite this article as: Gross et al:: Timing of antenatal care for adolescent and adult pregnant women in south-eastern Tanzania. BMC Pregnancy and Childbirth 2012 12:16.

\section{Submit your next manuscript to BioMed Central} and take full advantage of:

- Convenient online submission

- Thorough peer review

- No space constraints or color figure charges

- Immediate publication on acceptance

- Inclusion in PubMed, CAS, Scopus and Google Scholar

- Research which is freely available for redistribution

Submit your manuscript at www.biomedcentral.com/submit 